Article

\title{
Citizen Innovation: Exploring the Responsibility Governance and Cooperative Mode of a "Post-Schumpeter" Paradigm
}

\author{
Jin Chen, Linghui Han and Guannan $Q \mathbf{u} *$ (D) \\ School of Economics and Management, Tsinghua University, Beijing 100084, China; \\ chenjin@sem.tsinghua.edu.cn (J.C.); hanlh.18@sem.tsinghua.edu.cn (L.H.) \\ * Correspondence: qugn.17@sem.tsinghua.edu.cn
}

Received: 7 September 2020; Accepted: 24 November 2020; Published: 1 December 2020

check for updates

\begin{abstract}
It has become a burgeoning trend for the innovation paradigm to shift from producer-dominant to non-producer centric. Based on a critical review of the non-producer innovation literature, we identified several limitations of existing non-producer innovation paradigms-grassroots innovation, free innovation, common innovation, and social innovation-along two critical dimensions: responsibility governance of innovation outcomes and effective organizing form for collaborative innovation. To address the theoretical gaps in existing non-producer innovation research, we propose citizen innovation $(\mathrm{CI})$ as a new integrated innovation paradigm to balance these two dimensions by focusing on citizens' unique role as innovators. In the paper, we discuss CI's theoretical framework from three aspects: (1) citizen participation in innovation; (2) open collaborative innovation as the organizing form; (3) the process and incentive mechanisms of citizen innovation. We also offer two real-world examples to support the main propositions and mechanisms of CI. To conclude, we reflect on the limitations of the current research and discuss future directions for $\mathrm{CI}$ research.
\end{abstract}

Keywords: citizen innovation; non-producer innovation; open collaboration; innovation paradigm

\section{Introduction}

Edmund Phelps, the 2006 Nobel Laureate in Economic Science, believes that "the recognition by a people that their prosperity depends on the breadth and depth of their innovative activity is of huge importance" [1]. It has become a widely accepted premise that innovation is the main driving force not only for the prosperity of the economy and society but also for the continuous progression of human civilization [2]. With the prosperity of the knowledge economy and development of information and communication technology, it has become an inevitable trend for innovation paradigms to shift from the producer to non-producers. Existing non-producer innovation paradigms attempted to provide theoretical foundations for acquiring and transforming dispersed individual tacit knowledge into innovations. For example, grassroots innovation explores bottom-up non-producer innovation that contributes to the improvement of sustainability; free innovation and common innovation focus on individual innovation efforts and outcomes in the household sector or in their daily life; social innovation discusses innovation performed by social organizations towards a social end. What these innovation paradigms have in common is that they are all situated in a specific context. Although the previously mentioned non-producer innovation paradigms have effectively explored the potential of dispersed individual tacit knowledge, there are few discussions about how to provide explicit governance mechanisms to ensure that a particular innovation will produce positive externalities from a broader social standpoint. Existing research does not provide effective organization forms for collaborative innovation, which has substantial positive economic and social potential. 
To fill the gaps in existing non-producer innovation research, we introduce citizen innovation-a new innovation paradigm that focuses on citizens' unique role as innovators. The citizen innovation paradigm aims to provide an integrated theoretical framework that emphasizes both the "voice" and "duties" of individual participation in innovative activities. On the one hand, it is important to encourage individuals' participation in innovation and the voluntary revelation of relevant knowledge for an innovation. That way, the dispersed individual tacit knowledge embodied in citizens can be effectively identified and utilized. On the other hand, even more important is for innovators to take explicit and direct responsibility for their innovation outcomes' consequences.

This paper is organized into four parts. It begins with a brief literature review of the innovation paradigm shifting from producer innovation to non-producer innovation. Based on a critical review of the existing non-producer innovation paradigms of grassroots innovation, free innovation, common innovation, and social innovation, we identified their limitations that call for an integrated non-producer innovation framework. In the second section, we introduce the citizen innovation paradigm and discuss citizens' participation in innovation, the organization form to facilitate collaborative non-producer innovation, and the process and incentive mechanism of citizen innovation. Next, we offer two examples of citizen innovation's real-world application. In the last section, we summarize our propositions and main contributions by introducing the citizen innovation paradigm, followed by a discussion of the limitations of the current research and its possible future directions.

\section{Literature Review: From Producer Innovation to Non-Producer Paradigms}

In his theory of innovation, entrepreneurship, and economic development, Joseph Schumpeter placed producers at the center of economic development [3]. Since then, academics, policymakers, and practitioners have long perceived innovation by producers as the primary mode of innovation in market economies. This producer model assumes that producer firms are the primary source of the most important designs [4]. A few well-known producer innovators include companies who have founded Watson and Sarnoff Lab. These large producer firms invested heavily in hiring industry experts and acquiring cutting-edge equipment when establishing their internal R\&D departments. By controlling the innovation process within their organizational boundaries-from idea generation and commercialization to product marketing and sales distribution [5] - they achieved dominance of innovation in their respective industries.

Innovation is a complex knowledge recombination process [6]. The traditional producer innovations prevalent in the early and middle of the 20th century are boundary-closed, since knowledge flows are confined within organizations. However, with the rise of knowledge economies, producer innovators face more constraints and challenges when embedded in an environment with increased volatility, uncertainty, complexity, and ambiguity. Consequently, it has become a salient issue for producers to achieve even higher innovative efficiency by more effectively acquiring relevant knowledge. Over recent decades, scholars have paid increased attention to producer firms' need to transcend organizational boundaries and search for external knowledge and technology $[7,8]$. The introduction of open innovation by Chesbrough in 2003 initiated a new chapter of innovation research. It emphasizes the importance of external knowledge in producer firms' innovation process. Therefore, it is critical for focal producer firms to identify and assemble the knowledge relevant to an innovation across organizational boundaries [9]. However, identifying the location of relevant knowledge presents a great challenge for focal producer firms, especially when the knowledge is dispersed externally. Since individuals with relevant knowledge might be unknown to the focal firm, mechanisms of self-identification are vital.

As Polanyi said, "we can know more than we can tell" [10]. A significant amount of knowledge exists in a tacit form and is embodied in individuals. To fully utilize dispersed tacit knowledge among the general public and promote the self-identification of relevant knowledge owners to an innovation, scholars have explored and introduced several non-producer innovation paradigms. The introduction of user innovation in the 1970s by von Hippel represents a pioneering effort of innovation research 
beyond producers' purview. Users are defined as "firms or individual consumers that expect to benefit from using a design, a product, or a service". User innovation solves the knowledge acquisition problem in sticky information theory, especially for innovation scenarios where user demand information is crucial to innovation but prohibitive to acquire for producer innovators. User demand is a type of sticky information and can be critical for most products or service innovations. It usually derives from deeply embedded personal preferences that are difficult to be captured and expressed clearly. Thus, user demand information's tacit nature results in a high cost for it to be transferred to the producers. According to the sticky information theory, the high transfer cost of user demand information could change the problem-solving location from the producers to the users. Therefore, users as innovators select their own problems to explore out of their unique personal experiences. They usually start their innovation efforts by identifying an unsatisfied demand. Their search efforts of problem solutions are motivated either intrinsically or by benefits derived from using an innovation. Compared to producer innovation, user innovation enables an effective self-identification mechanism, which allows users to mobilize their tacit knowledge.

Along with the user innovation paradigm, recent decades have witnessed the emergence and development of several non-producer innovation paradigms: grassroots innovation, free innovation, common innovation, and social innovation (See Table 1).

Table 1. Representative non-producer paradigms of innovation.

\begin{tabular}{ccc}
\hline Representative Paradigm & Year & Author(s) \\
\hline Grassroots Innovation & 2007 & Seyfang and Smith \\
Free Innovation & 2017 & Von Hippel \\
Common Innovation & 2014 & Swann \\
Social Innovation & 2002 & MacCallum; Nicholls; and Murdock \\
\hline
\end{tabular}

Grassroots innovation is an important literature strand under the topic of cleaner production and sustainable development. It is defined as "a network of activists and organizations generating novel bottom-up solutions for sustainable development and sustainable consumption; solutions that respond to the local institution and the interests and values of the communities involved" [11]. Unlike other innovation paradigms in the private or public sector, it is the society instead of business or government that generates grassroots innovation [12]. Grassroots innovation draws from individuals' and communities' knowledge and experience that lies beyond the "formal institutions of education, research, and industry" [13]. The goal of grassroots innovation is to provide solutions to environmental sustainability for local communities. In contrast, the main goal of producer innovations or those in the public sector is the pursuing of commercial or state interests [14].

By taking various organizational paradigms and a bottom-up approach, grassroots innovation effectively identifies and aggregates the hidden dispersed individual knowledge in society. However, Grassroots innovation suffers from one limitation, that it has overlooked the responsibility governance aspect. Specifically, its theoretical framework lacks explicit mechanisms of governing individual innovators to avoid possible negative externalities. As a result, it cannot guarantee the responsibility for the innovation outcomes [15-18].

Free innovation refers to innovations in the household sector and are developed by individuals for personal or in-house use [19]. It differentiates from mainstream innovations in two aspects: (1) It is "free" and acquirable by others without payment. (2) It is entirely self-rewarded and developed at a consumer's own cost using their discretionary time. Common innovation was first introduced by Peter Swann in his 1994 book "Common Innovation: How We Create the Wealth of Nations". It is defined as the innovation "carried out by the common man and woman for their own benefit. It mostly takes place outside the domain of business, the professions or government" [20]. Common innovation focuses on innovations that are unexceptional but frequent. The primary purpose of common innovation is not 
only increased commercial performance and material wealth but also the growth of well-being and happiness- "R-Wealth" [20]. Similar to free innovation in the household sector, common innovation is not for a commercial end. In contrast to producer innovation, the innovator and consumer are the same economic entity in both common innovation and free innovation. Therefore, the individual innovator benefits directly from using his/her innovation. Furthermore, participation in innovation activities brings them the experience of "human flourishing" by increasing the innovator's well-being and happiness.

Free innovation and common innovation are both widespread innovation activities performed by individuals. However, these two innovation paradigms emphasize individual innovations, and it is unlikely for the atomized innovators under these two innovation paradigms to achieve effective knowledge sharing and collaborative problem-solving. Both innovation paradigms lack the incentives and organizations of collaborative innovation. An integrative framework that incorporates these aspects are yet to be explored.

Social innovation refers to innovations aiming towards a social end and diffuses predominantly through "organizations whose primary purposes are social" [21]. In contrast, producer innovation is motivated by profit-seeking purpose and diffuses through organizations whose primary purposes are profit maximization. Social innovation provides a theoretical framework to blur the boundaries between the public and private sectors so that innovative business processes and organizational paradigms can be applied to social innovations. Typical examples include fair trade products and microfinance.

Although the study of social innovation transcends the analytical framework of innovation for commercial ends, it resembles producer innovation with hierarchical organizations as the innovator. Thus, it shares the same dilemma as producer firms in identifying tacit knowledge relevant to solving a particular innovative problem. As a result, it is challenging for social innovation organizations to improve their innovation problem-solving efficiency by motivating the self-identification of innovators who possess relevant knowledge.

To sum up, it is a burgeoning trend for innovation research to shift from producer innovation to non-producer innovation. Acknowledging the tremendous innovative potential of dispersed individual tacit knowledge, scholars have explored several non-producer innovation paradigms to acquire and utilize this knowledge successfully. However, we consider existing non-producer innovation paradigms limited in two crucial aspects: (1) Lack of responsibility governance mechanism. For example, although grassroots innovation provides a useful way of motivating individuals to create bottom-up innovations by employing their personal tacit knowledge, it does not have a responsibility governance mechanism to prevent negative externalities resulting from grassroots innovation outcomes. (2) Absence of organizational paradigms that facilitate collaborative innovation. For instance, free innovation and common innovation depict the innovative activities performed by individuals who are common or in the household sectors. Despite their efficiency in motivating innovators to fully mobilize their individual tacit knowledge, both lack the organization form for individual innovators to collaborate effectively. To fill these gaps in existing non-producer innovation research, we propose an integrated innovation paradigm - citizen innovation that focuses on the acquisition and transformation of distributed individual tacit knowledge while incorporating the responsibility governance mechanism and an organization form that encourages collaborative innovation.

\section{The Conceptual Framework of Citizen Innovation}

In this section, we discuss the theoretical connotation of the citizen innovation paradigm from three dimensions. The first dimension focuses on the unique role of citizen participation in innovation activities. The second dimension is concerned with the appropriate organization form to facilitate collaborative knowledge sharing and efforts towards innovation. The third dimension reveals citizen innovation's process and incentive mechanism. 


\subsection{Citizen Participation in Innovation}

Citizenship refers to the status of a person recognized under law as "being a legal member of a sovereign state or belonging to a nation" [22]. Under social contract theory, a citizen has both rights and duties $[23,24]$. Citizens possess first-hand information about challenges experienced in their personal and social life.

From the development of citizens' participation in science, we can identify three stages: public understanding of science, public engagement with science, and citizen science [25]. Instead of accepting scientific knowledge passively or playing a peripheral role by providing data in scientific activities, citizens are more involved in the core scientific knowledge production process with the emergence and popularity of the citizen science movement. Although they may still need scientists' and experts' assistance in a research project, citizens now make decisions and find solutions for a scientific problem directly. Citizens' engagement in innovation activities has followed a similar path. Previous research defines citizen participation in social innovation as the many ways that more diverse actors can participate in developing innovative solutions to various challenges in society. Past work suggests that citizen engagement in social innovation has three main functions: information and resources provision, problem-solving, and decision making [26].

Research in social innovation and citizen science has noted that citizen engagement often provides abundant and valuable information and resources essential in an innovation or research projects $[26,27]$. They are especially useful in both the earlier stages of a project by helping with user needs identification and the later stages by facilitating evaluation collection. This paper focuses primarily on voluntary citizen participation in innovation's core knowledge recombination efforts—problem-solving, decision making, and solution implementation. By emphasizing citizen participation in innovation, citizen innovation encourages the self-identification of individuals who possess the knowledge relevant to an innovation problem or its solutions [6]. More importantly, it emphasizes the responsibility governance of innovation outcomes.

On the one hand, inspiring individuals to express their voices could lead to discovering diversified innovation opportunities based on each individual's unique knowledge and experiences. This variety helps prevent the "lock-in" problem that producer innovation often suffers from. The inclusiveness of citizen innovators with various backgrounds ensures exploration towards all possible directions. On the other hand, with both rights and duties incorporated in the role of citizen, they as innovators could "assume more direct and explicit responsibility for the consequences and uncertainties of their activities" [28]. Unlike free innovation or common innovation, citizen innovation is more about choosing problems and searching for solutions that are not only beneficial for the innovators but could also incur positive externalities.

\subsection{Open Collabarotive Community}

Citizen innovation also emphasizes collaborative knowledge sharing and innovation, the enormous positive economic and social potential of which is exemplified in ancient and modern times. Ancient Athens was one of the most influential poleis among the thousands of city states at its time with great military and economic success. Existing research has identified one driving force of these remarkable achievements being an efficient system that facilitates collaborative innovation by aggregating, coordinating, and regulating dispersed individual tacit knowledge. In the modern era, open source software projects have successfully harnessed the power of collaborative innovation and produced profound social and economic impacts. Well-known examples include Apache software projects and Linux user groups.

To achieve collaborative innovation, it is essential to search for the appropriate organization form that promotes the collaboration between individual innovators while still preserving their independent voice and passion for innovation. The new institutional economics offers an insightful discussion of organizational paradigms: market or hierarchies [29]. The hierarchical organization form aligns with the producer paradigm. In hierarchical organizations, the upper management members formulate 
innovative strategies carried out by industry experts and elites in the R\&D department. The chain of command is critical in internal organizing and communication. In hierarchical organizations, the boundaries of innovation activities are determined by relatively stable organization boundaries. On the contrary, individuals such as artists, writers, and designers perform innovation activities that occur in the market. In this scenario, the innovator is usually in charge of the whole process-from idea generation to implementation and commercialization. The relationship between individuals in the market is transactional instead of cooperative.

We propose open collaborative community as the appropriate organization form for citizen innovation. The rapid development of information and communications technology (ICT) has laid the technological foundations for this new organization form to emerge. Open collaborative community [30] consists of loosely connected participants attracted by similar goals or interests without physical organizations and geographical limitations. These participants are individual innovators empowered by easily accessible design and communication tools. Each innovator can work independently while collaborating with others at the same time on an innovation. Members of an open collaborative community usually communicate and interact virtually via online tools. Moreover, modular design architecture allows each participant's work output to be integrated into a more significant innovative project based on predefined interfaces and protocols.

The open collaborative community is different from either a hierarchical organization or the market. Compared to a hierarchical organization, open collaborative communities have a flat "peer group" structure without a chain of command or any leader with authority to issue orders. It also has a more dynamic and fluid boundary. In contrast to the market, a key difference is that open collaborative community supports and promotes collaborative knowledge sharing and innovation, while innovators transact with other individuals instead of collaborating in the market form.

In all, open collaborative community serves as an appropriate organization form for citizen innovation for the following reasons: (1) Its common peered structure emphasizes individual members' responsibility and rights to express their voice in innovation. (2) The modularity architecture allows participants to work independently while still collaborating with others to achieve common goals. Therefore, it balances individual divergent thinking and collective knowledge aggregation to achieve more responsible and impactful innovative outcomes.

\subsection{The Process and Incentive Mechanisms of Citizen Innovation}

\subsubsection{The Process of Citizen Innovation}

The dominant "producer" paradigm defines a closed innovation process with all innovative activities within the organization's boundary. These processes typically start with strategies formulated by the upper management and implementation carried out by industry experts in research and development departments. In the open innovation paradigm, although organizations seek knowledge and resources across the organization boundaries, they still control the innovation process.

Due to the highly uncertain nature of innovation, successful innovation output usually depends on a considerable number of attempts towards as many directions [31]. Empirical evidence has shown that the extent to which a company can achieve successful innovative outcomes is positively related to its degree of variety and breadth in knowledge search [32-34]. An increase in the number of knowledge sources will result in a higher chance of innovation success [35-37]. As researchers have concluded, organizations can explore a parallel search strategy $[38,39]$ to overcome uncertainty when engaging in innovation activities to better produce successful innovation outcomes.

Modularization is a crucial feature of the citizen innovation process. Individuals participating in a citizen innovation project can work parallel while collaborating with other members by integrating their modularized output into a more significant project. Instead of following orders from a chain of command, participants in citizen innovation projects take the initiative to work independently out of interest or sense-making purposes. They are more motivated to dig and invest their full potential in 
problem-solving and creative thinking related to innovative work. An open collaborative community of citizen innovation projects has the unique advantage of being able to assemble people with a highly diversified background, which is helpful for aggregating heterogeneous knowledge inside the community.

\subsubsection{The Incentive Mechanisms of Citizen Innovation}

We examine the incentive mechanisms of citizen innovators in this section. Specifically, we address a seldomly answered question: What drives individuals to participate in open collaborative communities that aim to create innovations for non-monetary purposes? According to economic theories, individuals' gain of utility can be multi-dimensional. In other words, individuals not only derive their incentive from monetary returns but also their psychological needs, such as self-actualization.

Past research has provided three models to describe how innovation can create economic benefits for the innovator, industry, and society: the private investment model, the collective investment model, and the private-collective model [40].

The private investment model rests on the assumption that private investors support innovation for practical purposes. To encourage investment from the private sector, public policies are formulated to protect private investors' rights in exclusively owning certain innovations within a limited time frame to ensure investors' profit from creating the innovation. However, the intellectual protection system excludes other parties from accessing and using the innovation, which causes social welfare loss. In the private investment model, society bears the loss incurred by the IP protection system.

In the collective investment model, the purpose of innovation is to provide public goods for society. According to Olsen's definition [41], public goods are defined by their non-exclusive and non-competitive nature. The collective investment model is based on innovators giving up the control of knowledge and assets to contribute them as public goods. This model can avoid social welfare losses in the private investment model. However, a significant flaw of the collective investment model is the difficulty in motivating potential contributors. It also faces significant challenges of the "free-riding" dilemma. Scientific research is an important example of a collective investment model. Scientists received funding and honors as incentives for conducting scientific research [42]. The fund issued by the public sector is an important means for scientists to publish their scientific discoveries publicly.

The third model is the private-collective model based on the following assumptions: First, the free revelation of valuable knowledge and innovation could benefit the creator. Second, the actual contributor to innovation will gain more than free riders. In the private-collective model, innovators are usually participating in an innovative collective effort by joining a community. Therefore, they could benefit from a network effect by revealing their innovation to a community freely. As Klandermanns and Hertel's studies [43,44] in social psychology and sociology literature have shown, the membership status is another reason for the innovators to contribute to innovative collective efforts in their community. Compared to the other models, the private-collective investment model solves the dilemma of creating public goods without sacrificing the innovator's benefits. This model also aligns with the motivation of citizen innovation.

According to Maslow's hierarchy of needs theory [45], human beings are motivated by five categories of needs: physiological, safety, love, esteem, and self-actualization. The highest level of need is self-actualization. It refers to the process in which an individual fully exerts his or her talent and potential. An individual can explore the potential of his/her talent and capabilities by solving complex problems and overcoming challenges. The more they uncover and unleash their potential, the more satisfaction they would gain. Therefore, engaging in innovative activities has a strong appeal to modern people by offering them an opportunity to utilize their talent and capabilities. Thus, it is important to encourage social values such as individual innovation, exploration, and self-actualization to bring vitality and welfare to society. 


\section{The Application of Citizen Innovation}

\subsection{Citizen Science}

According to the Citizen Science Association, citizen science is defined as "the involvement of the public in scientific research - whether community-driven research or global investigations" [27]. As SciStarter has explained, citizen science is "the public involvement in inquiry and discovery of new scientific knowledge", and there are four common characteristics of citizen science practices: "(1) anyone can participate; (2) participants use the same protocol so that data can be combined and be high quality; (3) data can help real scientists come to real conclusions; and (4) a wide community of scientists and volunteers work together and share data to which the public, as well as scientists, have access". The above characteristics are a display of the principles of the citizen innovation paradigm.

Citizen science can happen in diverse fields, including medicine, computer science, ecology, and astronomy. Furthermore, citizen science can take place at different scales-from local to continental and global scales and from a short time to over the course of decades.

Citizen science implements the citizen innovation paradigm in the scientific field, which provides the opportunity for joint engagement from professional scientists and the general public. It is an untraditional way to involve citizens, encourage curiosity, better understand science, and mobilize and integrate relevant knowledge.

For example, in coral reef studies, participative citizen science programs have been developed in the 21st century with the popularization of underwater photography. Citizens, together, can cover much more than professional scientists who cannot spend as much time in the field. Online communities supported by iNaturalist.org and the National Oceanic and Atmospheric Administration welcome volunteer participation in contributing images and observations to marine research projects. Community efforts have provided helpful information on reef health indicators and better imagery understanding of the Great Barrier Reef [46]. NOAA benefited from 137,000 h of research in 2016 [47].

\subsection{Open Source Software Projects}

In the past few decades, open source software has created significant economic value with well-known examples like Apache in the 1990s and, more recently, TensorFlow. It represents a successful application of the citizen innovation paradigm in organizing collective effort in the form of open collaboration community to create public goods.

The open source software community employs a classical form of open collaborative community. An open source community typically publishes a project online with a mission statement that can be as specific as technical details or as broad as only describing general tenets. Participants choose to join a project out of interest or other needs. An online open source community often includes members with diversified backgrounds from different geographical locations. The size of an open source community can range from dozens to thousands of people depending on the project's scale.

Offering free access to software is an important feature of open source software projects [48]. Contributors to open source software are required to publish their work freely to the open source community. Previous research on open source software projects has shown that innovators' motivations to reveal their work freely is not entirely based on maximizing financial gain but also on other non-monetary reasons. First, innovators can improve their code quality by publishing and reviewing it with other community members. This method can help the innovator learn and improve coding skills and benefit all users of the software. Second, early contributors who are the first people to publish their code serve as role models for followers in the open source communities. Other members would want to contribute in return after they have benefited from using the software. Finally, active participants in an open source software project can learn through online discussion and code reviews.

Participants in open source software projects can choose to work on a piece of code based on their interests and technical specialty. Then, they design and implement their code independently and publish code reviews after completion. The code is checked in after being approved by the code review 
to integrate it into the project's codebase. Other members act as gatekeepers through code reviews to prevent any bug or incorrect code being checked into the project's code repository. In most cases, an open source software project uses an online platform (e.g., GitHub) for task assignment, code review, and open discussion. In all, participants in an open source software project work independently and in parallel. They freely reveal their contribution by publishing the code and integrate it into the project's codebase so that the final output of the open source software project is public goods.

\section{Conclusions}

Innovation democratization has challenged the conventional model of producer innovation in which producers generate the most important innovations and pass them on to the customers as products or services. Scholars have paid increasing attention to the role of non-producers as innovators and explored their innovative potential by taking the angles of grassroots innovation, free innovation, common innovation, and social innovation. We conducted a literature review of existing non-producer innovation paradigms and identified their limitations in lacking responsibility governance mechanisms or overlooking collaborative innovation.

In this context, we introduced citizen innovation (CI) —a new innovation paradigm that emphasizes citizens' unique role in bottom-up innovative activities. Citizen innovation adopts open collaborative community as the organization form to promote collaborative innovation. Open collaborative community's peer-to-peer organizational structure strikes a delicate balance between effective aggregation of individual citizens' knowledge and maximization of participants' divergent thinking. We also examined the process and incentive mechanism of citizen innovation. On the one hand, we consider open collaborative sharing of knowledge, knowledge search towards various directions, and modularization as the most crucial features of the citizen innovation process. On the other hand, we conclude that citizens' participation in these innovative activities is motivated mostly by intrinsic reasons such as the psychological needs of self-actualization and a sense of "human flourishing", in contrast to producer/corporate innovators mainly benefiting from extrinsic monetary returns.

The introduction of citizen innovation and discussion of its theoretical framework makes several significant contributions. First, emphasizing citizens' engagement in innovation balances the effective utilization of dispersed personal knowledge and responsibility governance of innovation outcomes. The role of the citizen bears rights-voice and control in the process of innovation and responsibility—taking direct responsibility for the uncertainties and consequences of their activities. Second, examples like Wikipedia have proved the enormous positive economic and social potential of collaborative knowledge sharing and innovation. Citizen innovation adopts an open collaborative community as the organization form to facilitate collaborative innovation and promote individuals' voices in innovation. Although existing non-producer innovation encourages individuals' agency to mobilize their individual tacit knowledge fully, they lack the organization form for individual innovators to collaborate effectively. Exploring open collaborative community-a middle ground between hierarchical organizations and market in the organization form's spectrum brings non-producer innovation activity from individual to collaborative community levels. Third, it explores the process and incentive mechanism of citizen innovation. In all, the citizen innovation paradigm offers an integrated non-producer innovation framework that balances the effective utilization of dispersed knowledge among the citizen and the unifying of "voice" and "duty" in innovation.

Although we offer two real-world applications of citizen innovation, this research still lacks empirical evidence to support its fundamental mechanisms and conclusions. Future research is encouraged to test the citizen innovation framework's propositions and mechanisms with quantitative or qualitative data. A critical puzzle remains around the antecedents of citizen innovation. Future research should also examine what types of technological, cultural, or institutional environments are more likely to lead to citizen innovation.

The direct participation democracy brought unrivaled prosperity to ancient Athens. In the modern era, open source software projects like Wikipedia have created significant economic value and social 
welfare improvement. Both history and practice have confirmed the enormous innovative potential of mobilizing distributed knowledge among citizens. We hope the citizen innovation paradigm will advance the innovation democratization trend and expand the academic research focus on innovation from producers to citizens.

Author Contributions: Conceptualization, J.C., L.H. and G.Q.; investigation, L.H.; writing-original draft preparation, L.H.; writing-review and editing, J.C., L.H. and G.Q.; supervision, J.C.; project administration, L.H.; funding acquisition, J.C. All authors have read and agreed to the published version of the manuscript.

Funding: This paper was presented as a keynote speech of SOItmc 2020, and the publishing fee was supported by SOItmC. This research was funded by National Philosophy and Social Sciences Major Fund, grant number 17ZDA082; National Natural Science Foundation of China, 71941026.

Conflicts of Interest: The authors declare no conflict of interest.

\section{References}

1. Phelps, E.S. Mass Flourishing: How Grassroots Innovation Created Jobs, Challenge, and Change; Princeton University Press: Princeton, NJ, USA, 2013.

2. Chen, J. Technological innovation studies for super innovative nation. Technol. Econ. 2015, 34, 1-4.

3. Schumpeter, J.A. The Theory of Economic Development; Harvard University Press: Cambridge, MA, USA, 1934.

4. Baldwin, C.; Von Hippel, E. Modeling a paradigm shift: From producer innovation to user and open collaborative innovation. Organ. Sci. 2011, 22, 1399-1417. [CrossRef]

5. Von Hippel, E. Democratizing innovation: The evolving phenomenon of user innovation. J. Betr. 2005, 55, 63-78. [CrossRef]

6. Felin, T.; Zenger, T.R. Closed or open innovation? Problem solving and the governance choice. Res. Policy 2014, 43, 914-925. [CrossRef]

7. Enkel, E.; Gassmann, O.; Chesbrough, H. Open R\&D and open innovation: Exploring the phenomenon. R D Manag. 2009, 39, 311-316. [CrossRef]

8. Huizingh, E.K.R.E. Open innovation: State of the art and future perspectives. Technovation 2011, 31, 2-9. [CrossRef]

9. Romero-Rodríguez, J.-M.; Ramírez-Montoya, M.-S.; Aznar-Díaz, I.; Hinojo-Lucena, F.-J. Social Appropriation of Knowledge as a Key Factor for Local Development and Open Innovation: A Systematic Review. J. Open Innov. 2020, 6, 44. [CrossRef]

10. Polanyi, M. The Tacit Dimension; Peter Smith: Gloucester, MA, USA, 1983.

11. Seyfang, G.; Smith, A. Grassroots innovations for sustainable development: Towards a new research and policy agenda. Environ. Politics 2007, 16, 584-603. [CrossRef]

12. Tang, T.; Karhu, K.; Hamalainen, M. Community innovation in sustainable development: A cross case study. World Acad. Sci. Eng. Technol. 2011, 73, 396-403.

13. Reinsberger, K.; Brudermann, T.; Hatzl, S.; Fleiß, E.; Posch, A. Photovoltaic diffusion from the bottom-up: Analytical investigation of critical factors. Appl. Energy 2015, 159, 178-187. [CrossRef]

14. Yalçın-Riollet, M.; Garabuau-Moussaoui, I.; Szuba, M. Energy autonomy in Le Mené: A French case of grassroots innovation. Energy Policy 2014, 69, 347-355. [CrossRef]

15. Owen, R.; Macnaghten, P.; Stilgoe, J. Responsible research and innovation: From science in society to science for society, with society. Sci. Public Policy 2012, 39, 751-760. [CrossRef]

16. von Schomberg, R. A Vision of Responsible Research and Innovation; John Wiley \& Sons, Ltd.: Chichester, UK, 2013. [CrossRef]

17. Rodríguez, H.; Fisher, E.; Schuurbiers, D. Integrating science and society in European Framework Programmes: Trends in project-level solicitations. Res. Policy 2013, 42, 1126-1137. [CrossRef]

18. Sharif, M.N. Technological innovation governance for winning the future. Technol. Forecast. Soc. Chang. 2012, 79, 595-604. [CrossRef]

19. Von Hippel, E. Free Innovation; MIT Press: Cambridge, MA, USA, 2017.

20. Swann, P.G. Common Innovation: How We Create the Wealth of Nations; Edward Elgar Publishing: Cheltenham, UK, 2014.

21. Murray, R.; Caulier-Grice, J.; Mulgan, G. The Open Book of Social Innovation; The Young Foundation: London, UK, 2010.

22. Caves, W.R. Encyclopedia of the City; Routledge: London, UK, 2004. [CrossRef] 
23. Cairns, A.C.; Courtney, J.C.; MacKinnon, P. Citizenship, Diversity and Pluralism: Canadian and Comparative Perspectives; McGill-Queen's University Press: Montreal, QC, Canada; Kingston, ON, Canada, 2000.

24. Nikolay, I.D.; Gulnara, F.R.; Djamilia, F.S.; Sergei, V.K. Dynamics of Trust in Institutions, the Legitimacy of the Social Order, and Social Open Innovation. J. Open Innov. 2020, 6, 111. [CrossRef]

25. Audétat, M. Re-Thinking Science, Re-Thinking Society. Soc. Stud. Sci. 2001, 31, 950-956. [CrossRef]

26. Davies, A.; Simon, J. Engaging Citizens in Social Innovation: A Short Guide to the Research for Policy Makers and Practitioners. A Deliverable of the Project: "The Theoretical, Empirical and Policy Foundations for Building Social Innovation in Europe" (Tepsie), European Commission-7th Framework Programme; European Commission, DG Research: Brussels, Belgium, 2013.

27. Citizen Science Association. Citizen Science. Available online: https://www.citizenscience.org/ (accessed on 7 August 2020).

28. Stirling, A. Towards Innovation Democracy? Participation, Responsibility and Precaution in the Politics of Science and Technology; STEPS Centre: Brighton, UK, 2015.

29. Williamson, O.E. Markets and hierarchies: Some elementary considerations. Am. Econ. Rev. 1983, 63, 316-325.

30. Levine, S.S.; Prietula, M.J. Open collaboration for innovation: Principles and performance. Organ. Sci. 2013, 25, 1414-1433. [CrossRef]

31. Ahuja, G.; Morris Lampert, C. Entrepreneurship in the large corporation: A longitudinal study of how established firms create breakthrough inventions. Strateg. Manag. J. 2001, 22, 521-543. [CrossRef]

32. Katila, R.; Ahuja, G. Something old, something new: A longitudinal study of search behavior and new product introduction. Acad. Manag. J. 2002, 45, 1183-1194.

33. Ahuja, G.; Katila, R. Technological acquisitions and the innovation performance of acquiring firms: A longitudinal study. Strateg. Manag. J. 2001, 22, 197-220. [CrossRef]

34. Rosenkopf, L.; Nerkar, A. Beyond local search: Boundary-spanning, exploration, and impact in the optical disk industry. Strateg. Manag. J. 2001, 22, 287-306. [CrossRef]

35. Laursen, K.; Salter, A. Open for innovation: The role of openness in explaining innovation performance among UK manufacturing firms. Strateg. Manag. J. 2006, 27, 131-150. [CrossRef]

36. Nelson, R.R. Uncertainty, learning, and the economics of parallel research and development efforts. Rev. Econ. Stat. 1961, 43, 351-364. [CrossRef]

37. Veugelers, R.; Cassiman, B. Make and buy in innovation strategies: Evidence from Belgian manufacturing firms. Res. Policy 1999, 28, 63-80. [CrossRef]

38. Baldwin, C.Y.; Clark, K.B. Design Rules: The Power of Modularity; MIT Press: Cambridge, MA, USA, $2000 ;$ Volume 1.

39. Baldwin, C.Y.; Clark, K.B. Managing in an age of modularity. Manag. Modul. Age Archit. Netw. Organ. 2003, 149, 84-93.

40. Von Hippel, E.; Von Krogh, G. Open source software and the "private-collective" innovation model: Issues for organization science. Organ. Sci. 2003, 14, 209-223. [CrossRef]

41. Olson, M. The Logic of Collective Action; Harvard University Press: Cambridge, MA, USA, 2009; Volume 124.

42. Audretsch, D.B.; Stephan, P.E. Company-scientist locational links: The case of biotechnology. Am. Econ. Rev. 1996, 86, 641-652.

43. Klandermans, P.G. The Social Psychology of Protest; Blackwell: Oxford, UK, 1997.

44. Hertel, G.; Niedner, S.; Herrmann, S. Motivation of software developers in Open Source projects: An Internet-based survey of contributors to the Linux kernel. Res. Policy 2003, 32, 1159-1177. [CrossRef]

45. Maslow, A.H. Motivation and Personality; Harper \& Row: New York, NY, USA, 1970; pp. 187-202.

46. Diver, V.R. Researching the Great Barrier Reef. Available online: https://www.virtualreef.org.au/research/ (accessed on 7 August 2020).

47. National Oceanic and Atmospheric Administration (NOAA). Get Involved: Volunteer Opportunities; NOAA: Washington, DC, USA, 2020.

48. Raymond, E. The cathedral and the bazaar. Knowl. Technol. Policy 1999, 12, 23-49. [CrossRef]

Publisher's Note: MDPI stays neutral with regard to jurisdictional claims in published maps and institutional affiliations. 